\title{
APLIKASI E-MONEY PADA PASAR MAHASISWA SEKOLAH TINGGI TEKNOLOGI INDONESIA TANJUNGPINANG
}

\author{
Dwi Nurul Huda ${ }^{1}$, Danandjaya Saputra ${ }^{2}$, Suyamto Widodo ${ }^{3}$ \\ 1,2,3 Jurusan Teknik Informatika STT Indonesia Tanjungpinang \\ Jln. Pompa Air No. 28 Tanjungpinang Kepulauan Riau Indonesia \\ ${ }^{1}$ suyamtowidodo@gmail.com \\ ${ }^{2}$ dwinurul@sttindonesia.com
}

\begin{abstract}
Intisari- Pada kegiatan pasar mahasiswa pembayaran tidak dilakukan dengan menggunakan mata uang rupiah melainkan menggunakan koin yang disediakan oleh panitia sebagai alat tukar pada proses jual beli di dalam pasar mahasiswa. Penggunaan koin dalam proses jual beli dinilai kurang efektif dan efisien maka dari itu dikembangkanlah aplikasi yang memakai konsep E-money sebagai pengganti penggunaan koin. Aplikasi ini dirancang menggunakan Bahasa pemrograman php dan MySql sebagai basis data, kemudian untuk Text editor menggunakan Notepad++ dan MySql front untuk editor basis data dengan menggunakan metode waterfall sebagai pengembangan perangkat lunak.Penelitian ini menghasilkan suatu program yang dapat melakukan pengolahan data pembeli, pemilihan menu dan laporan penjualan serta pembelian . program ini dapat memantau segala transaksi yang terjadi antara pembeli maupun penjual sehingga meminimalisir kesalahan kesalahan yang dapat terjadi pada pasar mahasiswa Sekolah Tinggi Teknologi Indonesia Tanjungpinang.
\end{abstract}

Kata Kunci :E-Money, PHP, Website, E-Commerce

Abstract - In student market activities payments are not made using the rupiah but use coins provided by the committee as a medium of exchange in the buying and selling process in the student market. The use of coins in the buying and selling process is considered to be less effective and efficient and therefore applications are developed that use the concept of E-money as a substitute for the use of coins. This application is designed using PHP and MySql programming languages as a database, then for Text editors using Notepad ++ and MySql front for database editors using the waterfall method as software development.This research resulted in a program that can perform data processing of buyers, selection of menus and reports on sales and purchases. this program can monitor all transactions that occur between buyers and sellers so as to minimize the mistakes that can occur in the student market of the Sekolah Tinggi Teknologi Indonesia Tanjungpinang.

Keywords - E-Money ,PHP, Website, E-Commerce

\section{Pendahuluan}

Kemajuan dalam kegiatan industri pada beberapa aspek memerlukan manajemen atau pengelolaan yang dituntut memiliki kinerja, kecermatan, keekonomisan, keterpaduan, kecepatan, ketepatan, ketelitian serta keamananan yang tinggi dalam rangka memperoleh hasil akhir yang sesuai harapan. Pengelolaan suatu kegiatan dengan investasi berskala besar dan tingkat kompleksitas yang sangat sulit membutuhkan cara teknis/metode yang teruji, sumber daya yang berkwalitas, serta penerapan ilmu pengetahuan yang tepat dan up to date.

Ilmu Pengetahuan dan Teknologi yang semakin berkembang seiring dengan perkembangan zaman yang semakin pesat, membuat lembaga akademis diharuskan dapat membentuk generasi-generasi yang mumpuni dan siap menghadapi laju perubahan zaman. Menanggapi gejolak dan perubahan ini Sekolah Tinggi Teknologi Indonesia selaku lembaga akademis yang berpusat dibidang teknologi informasi menerapkan kurikulum yang sesuai dengan kebutuhan yang dibutuhkan. Salah satu mata kuliah yang ada dalam kurikulum tersebut adalah Mata Kuliah Kewirausahaan.

Mata Kuliah Kewirausahaan terbagi menjadi kewirausahaan 1 dan kewirausahaan 2 yang dipelajari pada semester 4 dan 5. Dalam rangka penilaian mata kuliah ini STT Indonesia menggelar pasar mahasiswa yang dilaksanakan setiap tahunnya. Pada saat bertransaksi di pasar mahasiswa, seluruh pengunjung diharuskan membeli koin yang telah disediakan, yang mana dapat digunakan sebagai alat transaksi di kegiatan ini. Penggunaan koin ini dilakukan agar pihak penyelenggara dapat memonitor jumlah uang yang beredar di pasar mahasiswa STT Indonesia ini.

Jumlah koin yang terbatas mengakibatkan pihak penyelenggara menyedikan panitia khusus yang bertugas menukar koin dari stand peserta bazar dengan nota, yang mana koin tersebut akan kembali di jual di kasir, hal ini menimbulkan masalah baru seperti peserta bazar kehilangan nota, kesalahan pencatatan, koin yang hilang dan lain sebagainya.

Menurut penyelenggara pasar mahasiswa STTI Tanjungpinang beberapa masalah yang ada diantaranya adalah sistem transaksi masih menggunakan manual yaitu berupa uang kertas atau koin dan sistem pendataan penukaran uang masih manual yaitu dengan cara mencatat berapa uang asli yang ditukarkan dengan uang pasar mahasiswa berupa koin yang dikeluarkan oleh pihak penyelanggara, proses pembukuan yang masih menggunakan cara rekap data setiap transaksinya agar bisa mengetahui jumlah transaksi masuk dan transaksi keluar pada stand - stand yang terdaftar.

Proses pembukuan yang masih menggunakan cara rekap data banyak memakan waktu jadi tidak efisien, beresiko tinggi seperti basah, rusak, robek, hilang, maupun kemungkinan buruk lainnya. Maka dari itu masalah yang penulis ingin mengembangkan menjadi sistem yang otomatis dan secara komputerisasi yang dapat dilihat secara langsung jumlah transaksi yang masuk ,transaksi yang keluar, dan penukaran uang pada pasar mahasiswa tersebut. 
Oleh karena itu diperlukan suatu aplikasi yang dapat menggantikan fungsi koin yang mana jumlahnya tidak terbatas dan agar dapat termonitor dengan baik sehingga mempermudah transaksi di pasar mahasiswa STT Indonesia Tanjungpinang.

\section{Metodologi Penelitian}

Merupakan suatu teknik atau cara untuk mengumpulkan data atau fakta yang nantinya akan dipelajari dan akhirnya sebagai bahan untuk di analisa serta digunakan untuk memudahkan pencarian dan pemecahan suatu masalah.

\section{Metode Pengumpulan Data}

Metode pengumpulan data yang digunakan dalam penelitian ini adalah sebagai berikut :

\section{a. Studi Literatur}

Studi Literatur (library research) adalah teknik pengumpulan data dengan cara mengumpulkan literatur, jurnal, paper dan bacaan-bacaan yang ada kaitannya dengan judul penelitian.

\section{b. Observasi}

Teknik pengumpulan data dengan mengadakan penelitian dan peninjauan langsung terhadap permasalahan yang diambil.

c. Interview

Teknik pengumpulan data dengan mengadakan tanya jawab secara langsung yang ada kaitannya dengan topik yang diambil.

\section{Metode Pembangunan Perangkat Lunak}

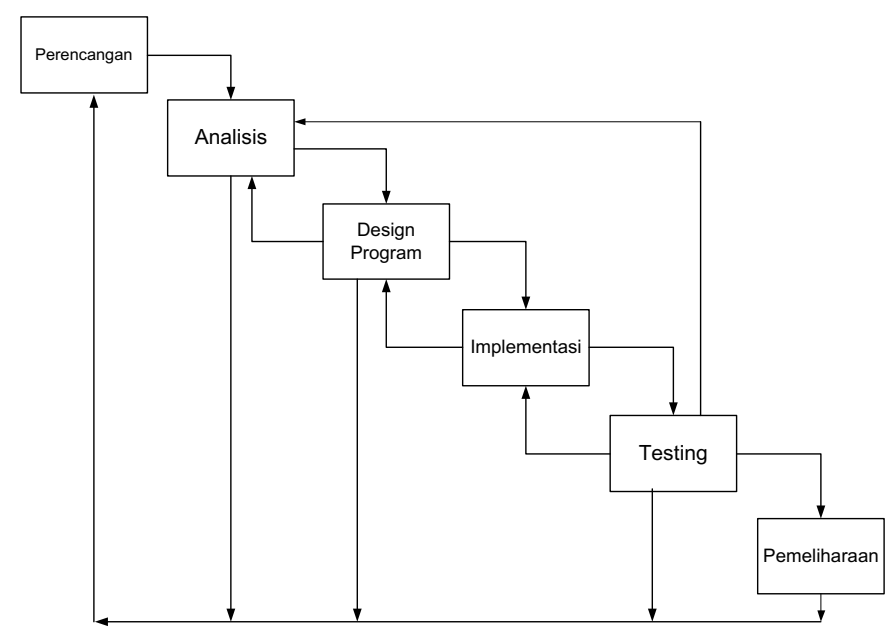

Gambar 1. Model Pengembangan Air Terjun

Teknik analisis data dalam pembangunan perangkat lunak menggunakan model waterfall menurut Adi Nugroho, yang meliputi beberapa proses diantaranya yaitu :

a. Perancangan dan analisis

Mengumpulkan kebutuhan secara lengkap kemudian dianalisis dan didefinisikan kebutuhan yang harus dipenuhi oleh program yang akan dibangun. Fase ini harus dikerjakan secara lengkap untuk bisa menghasilkan desain yang lengkap. b. Design Sistem dan Program

Desain dikerjakan setelah kebutuhan selesai dikumpulkan secara lengkap.

\section{c. Implementasi}

Desain program diterjemahkan ke dalam kode-kode dengan menggunakan bahasa pemrograman yang sudah ditentukan. Program yang dibangun langsung diuji baik secara unit.

d. Integrasi dan testing

Penyatuan unit-unit program kemudian diuji secara keseluruhan (sistem testing).

\section{e. Pemeliharaan}

Mengoperasikan program di lingkungannya dan melakukan pemeliharaan, seperti penyesuaian atau perubahan karena adaptasi dengan situasi sebenarnya.

\section{III.HASil dan PEMbahasan}

A. Perancangan Sistem

Perancangan sistem adalah tahap selanjutnya setelah analisa sistem, mendapatan gambaran dengan jalan tentang apa yang dikerjakan pada analisa sistem. Perancangan sistem meliputi perancangan diagram konteks, flowmap, Data flow diagram, entity relationship diagram, dan perancangan perangkat lunak.

B. Prosedur Yang Diusulkan

Perancangan prosedur yang diusulkan merupakan aktifitas perancangan terhadap prosedur-prosedur yang diusulkan untuk diterapkan pada sistem yang akan dibangun. Adapun tujuan dari perancangan prosedur-prosedur ini adalah untuk meningkatkan efisensi dan efektifitas perusahaan dalam mengatur manajemen data-data perusahaan

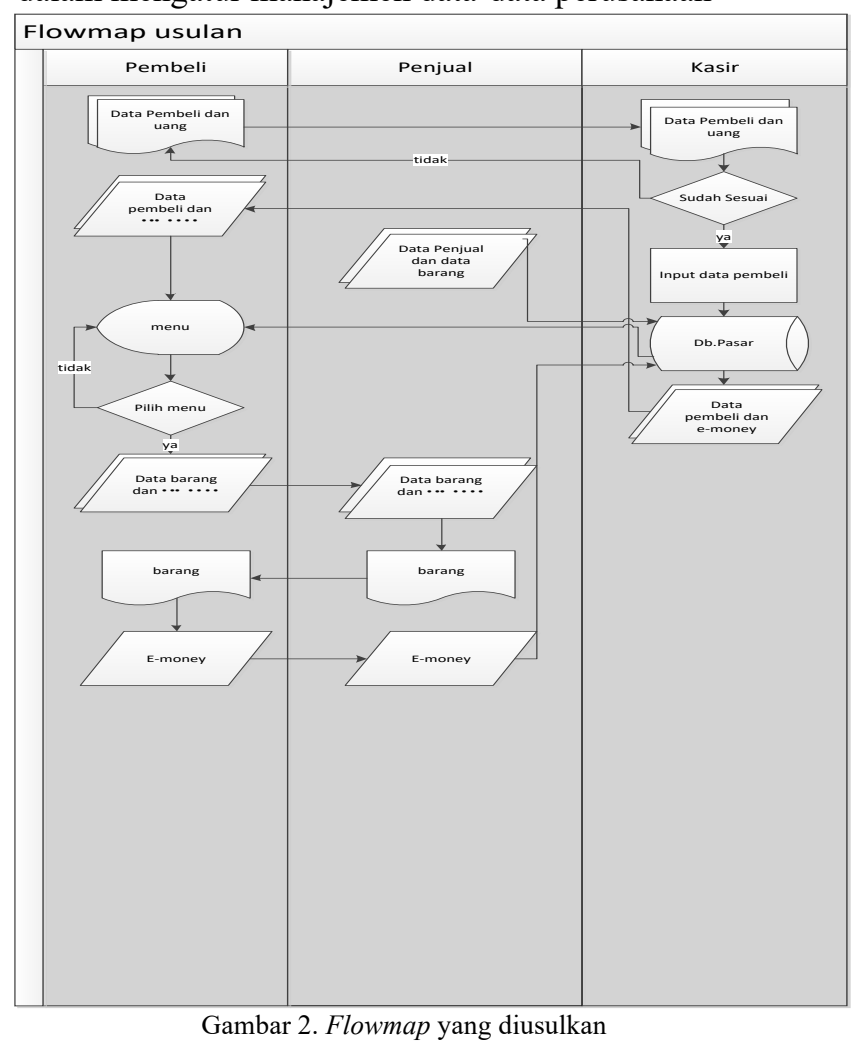


C. Diagram Konteks

Perancangan diagram konteks adalah perancangan yang menggambarkan proses dan ruang lingkup sistem. Diagram konteks ini akan menggambarkan keseluruhan input dan output sistem. Berikut perancangan diagram konteks aplikasi emoney pada pasar mahasiswa Sekolah Tinggi Teknologi Indonesia Tanjunugpinang dapat dilihat gambar dibawah ini :

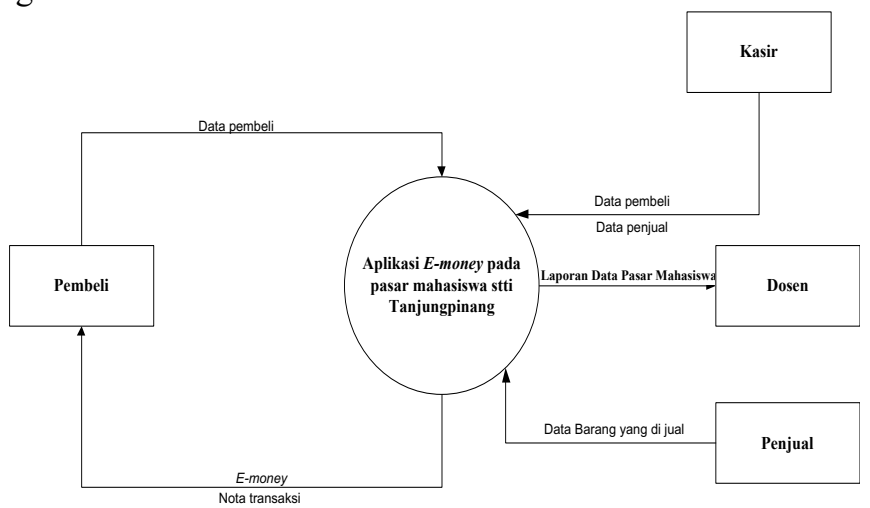

Gambar 3. Rancangan Diagram Konteks

\section{Data Flow Diagram}

cData Flow Diagram (DFD) adalah diagram yang digunakan untuk menggambarkan suatu sistem yang sudah jadi atau sistem yang baru dirancang yang akan dikembangkan secara logika, tanpa mempertimbangkan lingkungan fisik kemana data tersebut disimpan. Disamping itu ada Data flow Diagram (DFD) juga dapat menggambarkan arus data yang terstruktur dan jelas dari mulai pengisian data sampai dengan keluarannya.

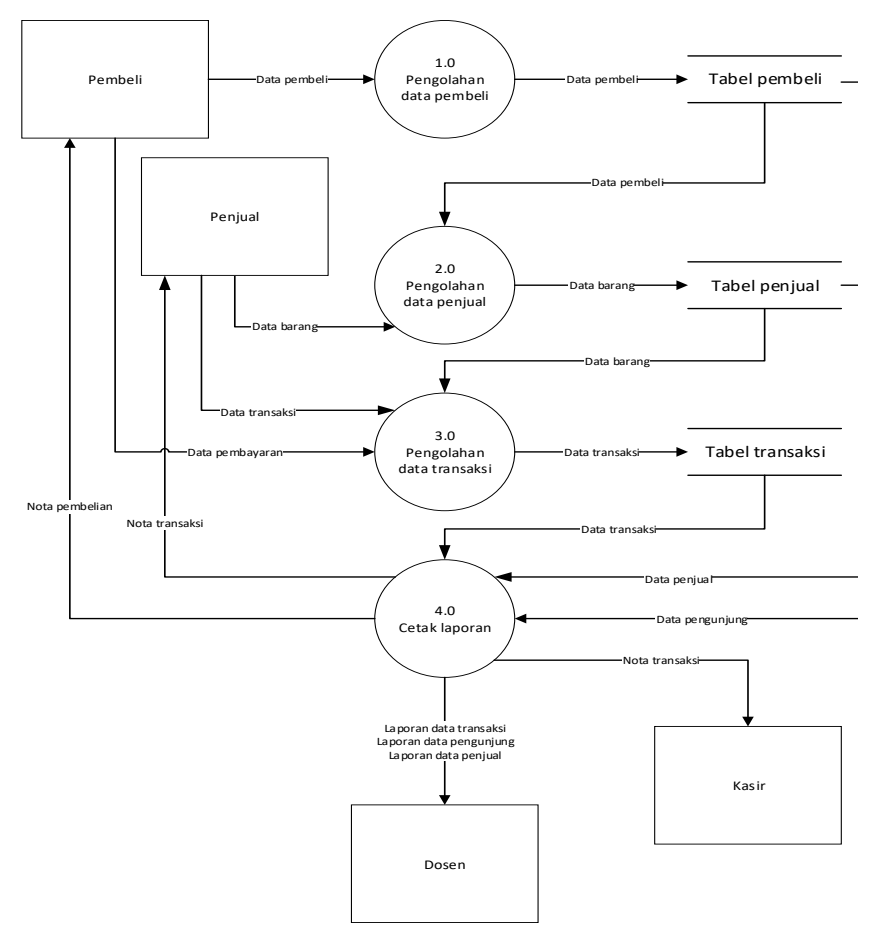

Gambar 4. Data Flow Diagram

\section{E. Entity Relationship Diagram}

Entity Relationship adalah salah satu metode pemodelan basis data yang digunakan untuk menghasilkan skema konseptual untuk jenis/model data semantik sistem. Dimana sistem seringkali memiliki basis data relasional, dan ketentuannya bersifat top-down. Diagram untuk menggambarkan model Entitiy-Relationship ini disebutEntitiy-Relationship diagram, ER diagram, atau ERD. Entity Relationship Diagram adalah diagram yang digunakan untuk memodelkan struktur data, sehingga dapat dilakukan pengujian Entity Relationship Diagram (ERD) pada dasarnya adalah diagram yang memperlihatkan entitas-entitas yang terlibat dalam suatu sistem serta hubungan-hubungan (relasi) antar entitas tersebut. Tekanan utama pada ERD adalah tabeltabel yang mempersentasikan relasi antar entitas itu sendiri.

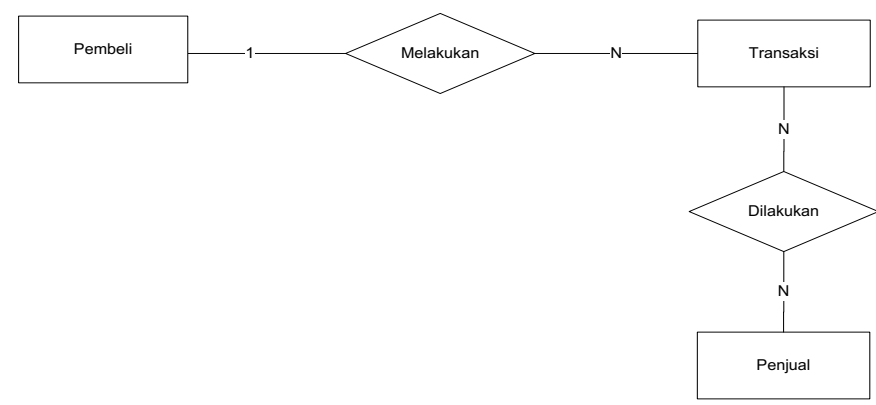

Gambar 5. Entity Relationship Diagram

\section{F. Strutur Program}

Struktur ini sering digunakan untuk mendefinisikan suatu record data yang disimpan di dalam file. Struktur program adalah suatu konsep pembuatan yang mempunyai fungsi untuk mengelompokkan instruksi kedalam sub program fungsional dimana setiap sub program tersebut memiliki tugas dan fungsi tertentu yang digunakan untuk mendukung dari keseluruhan program yang dibuat. Struktur program yang dibuat adalah sebagai berikut :

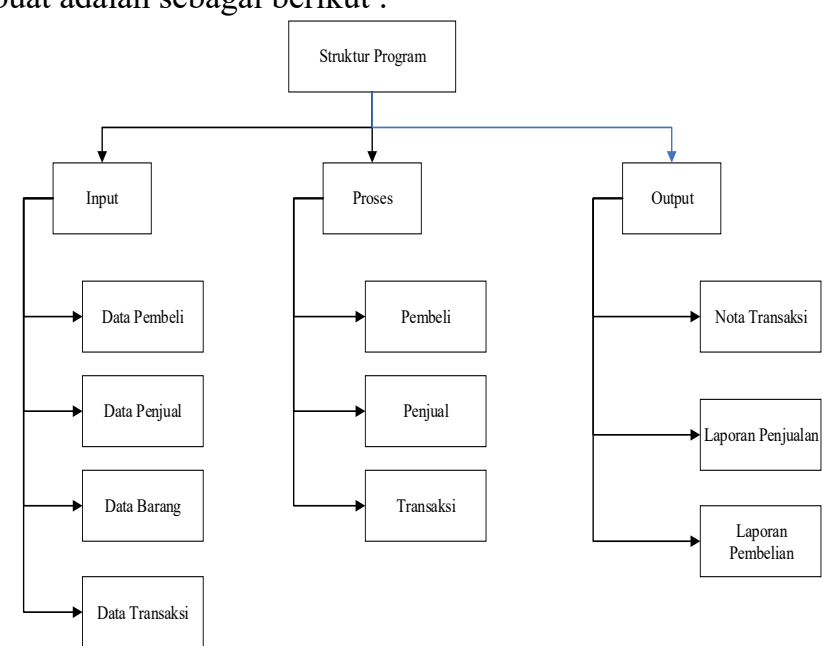

Gambar 6. Rancangan Struktur Program 


\section{G. Hasil Implementasi}

Tahapan implementasi merupakan kelanjutan dari kegiatan rancangan sistem dan dapat dipandang sebagai suatu usaha untuk mewujudkan sistem yang telah dirancang. Langkah langkah dari proses implementasi adalah urutan dari kegiatan awal sampai kegiatan akhir yang harus dilakukan untuk mewujudkan sistem yang dirancang. Hasil dari tahapan implementasi ini adalah suatu sistem pengolahan data yang sudah dapat berjalan dengan baik. Untuk itu agar suatu sistem pengolahan data dapat berjalan dengan baik diperlukan suatu ketelitian dalam penyusunan program. Kegitatan implementasi ini meliputi implementasi perangkat lunak (Implementasi Procedural), perangkat keras, uji coba program.

Dalam perencanaan implementasi sistem ada tiga landasan yang akan dikemukakan, yaitu :

1. Penjadwalan waktu kegiatan yang dilakukan dalam pembangunan sistem.

2. Menentukan waktu pelaksanaan suatu kegiatan.

3. Menentukan urutan pelaksanaan kegiatan yang telah di identifikasi.

Pada Sub bagian ini akan dijelaskan uraian tentang tahapan implementasi dari aplikasi e-money pada pasar mahasiswa STTI tanjungpinang. dimana aplikasi ini dikembangkan dan diimplementasikan dengan bahasa pemrograman visual PHP Native dengan database MySQL, serta web browser sebagai alat untuk mengakses web yang ada.

Perangkat keras yang minimal diperlukan untuk membangun aplikasi e-money pada pasar mahasiswa STTI tanjungpinang sesuai dengan rekomendasi minimum yaitu sebagai berikut :

1. Smartphone

2. Pc

3. Procesor Quad Core

4. Layar LCD 15 “

5. Harddisk terpasang $512 \mathrm{~GB}$

6. Memory RAM 1 GB

7. Mouse

8. Keyboard

9. Printer

\section{H. Interface Aplikasi}

Berikut tampilan halaman dari aplikasi E-Money Pasar Mahasiswa Sekolah Tinggi Teknologi Indonesia Tanjungpinang:

\section{Login}

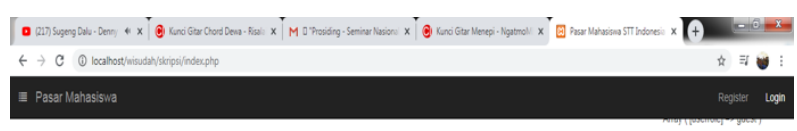

Pasar Mahasiswa STT Indonesia Tanjungpinang

Gambar 7. Halaman index.php

\section{Halaman Login}

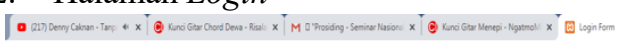
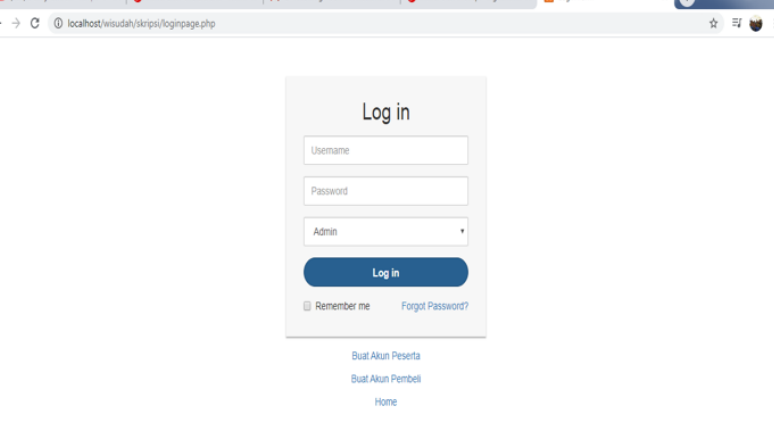

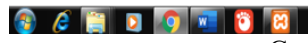

Gambar 8. Halaman Login

3. Halaman Registrasi Penjual

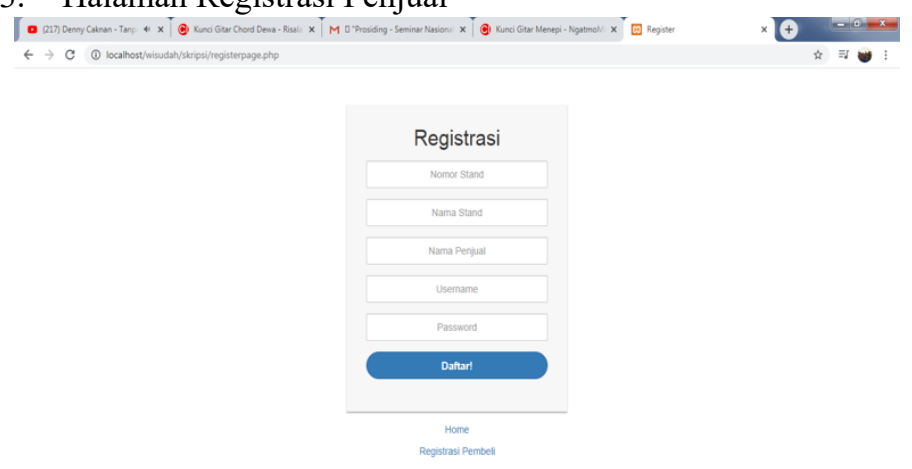

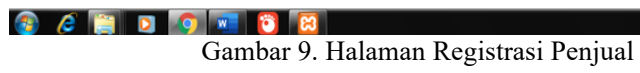

4. Halaman Registrasi pembeli 
Bangkit Indonesia, Vol. VIII, No. 02, Bulan Oktober 2019

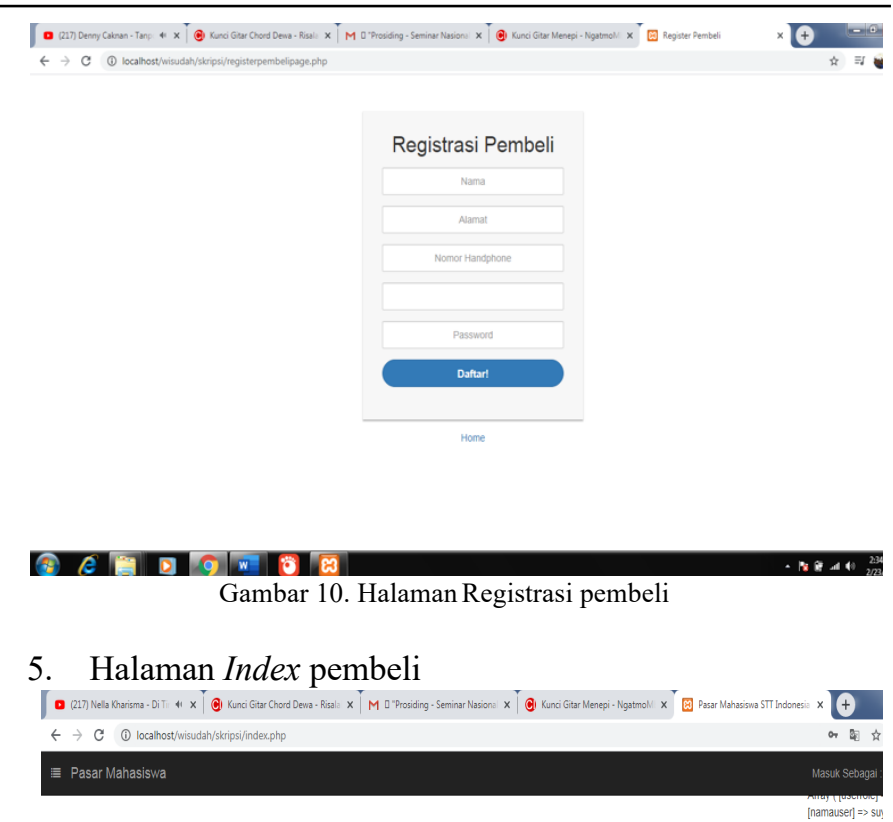

Pasar Mahasiswa STT Indonesia Tanjungpinang

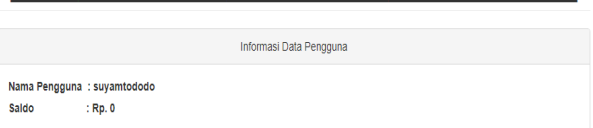

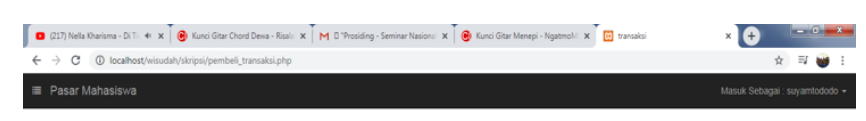

Transaksi

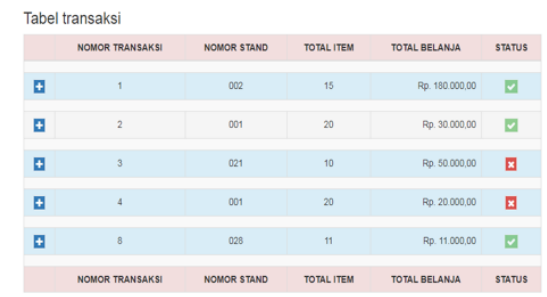

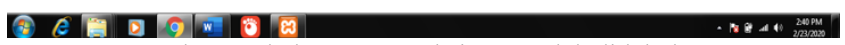

Gambar 13. halaman transaksi yang telah di lakukan

8. Halaman Index penjual

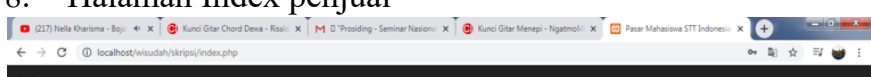

and

Pasar Mahasiswa STT Indonesia Tanjungpinang

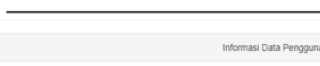

Nama Pengounas : Loins
Salso
:Rp. 228.000

\section{Rerpog का}

Gambar 11. Halaman Index pembeli

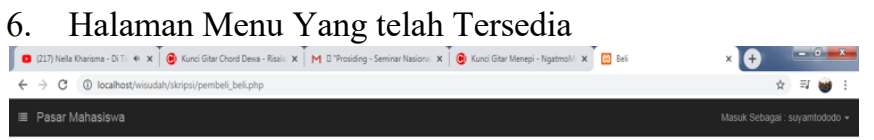

Menu

Tabel Menu

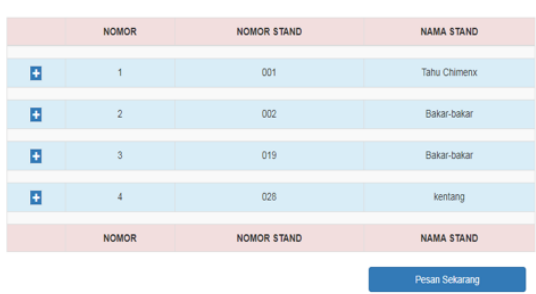

\section{A) है⿴囗十丁|क काल}

Gambar 12. Menu Yang telah Tersedia

7. Halaman Transaksi Yang Telah Dilakukan
9. Halaman menu Yang telah diisi oleh penjual

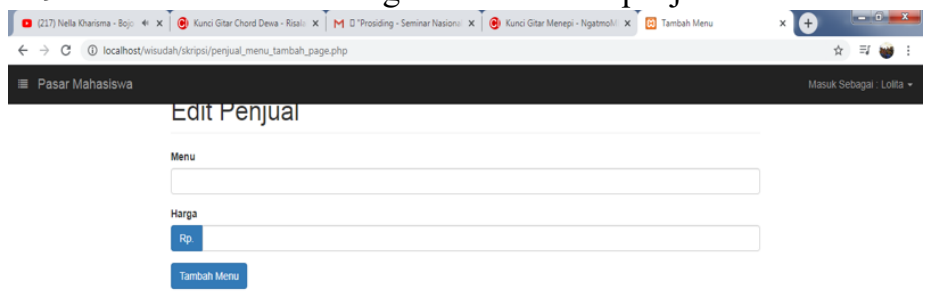




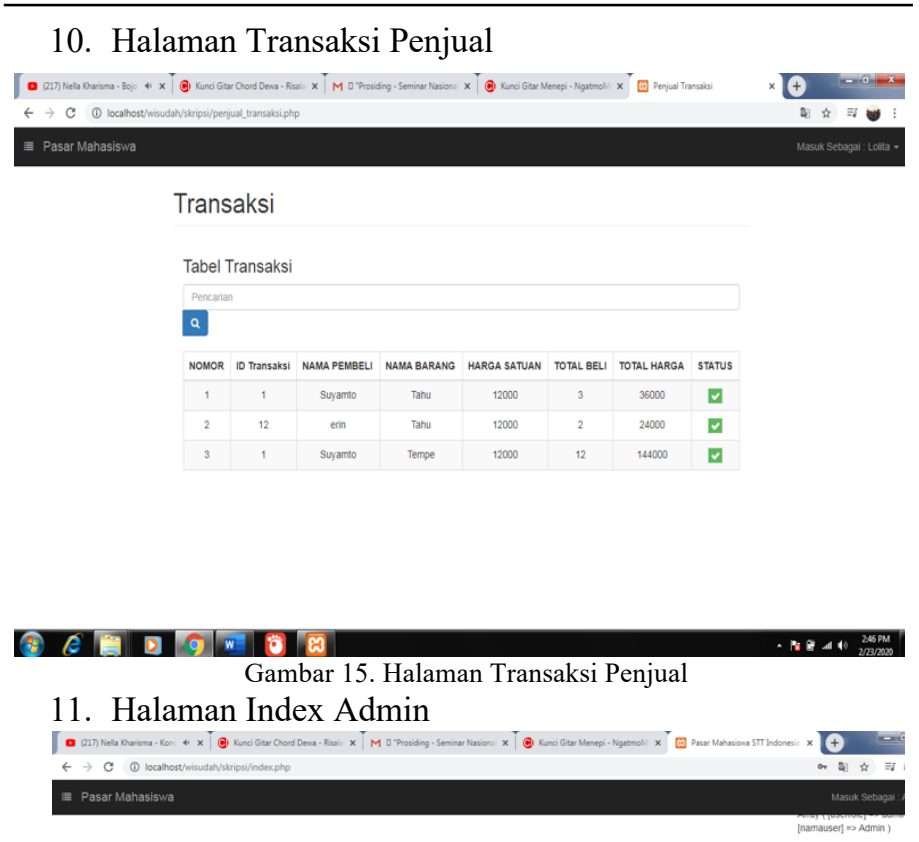

Pasar Mahasiswa STT Indonesia Tanjungpinang

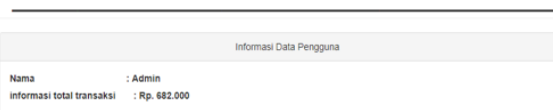

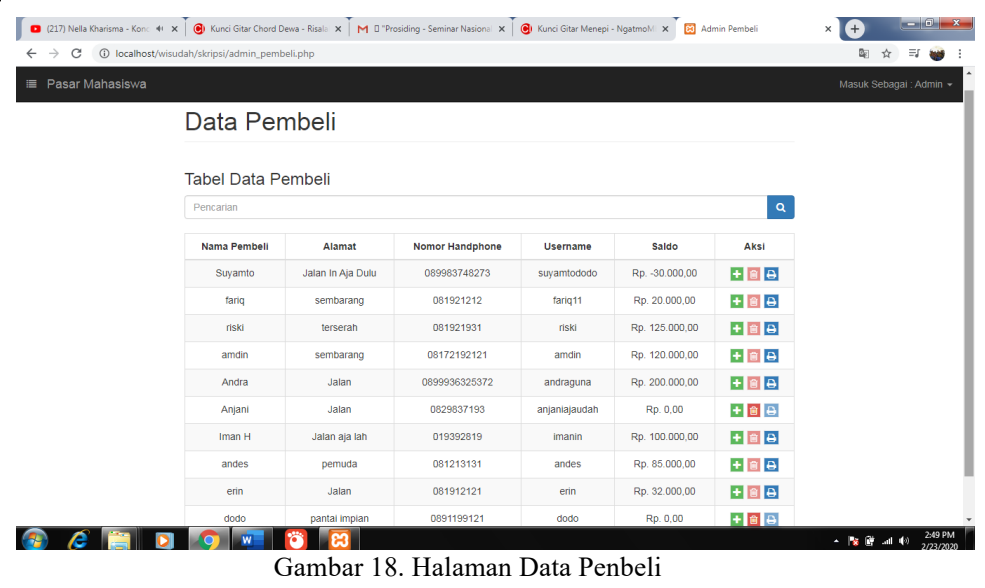

14. Halaman Tambah Saldo

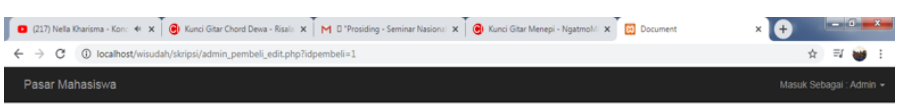

Tambah Saldo

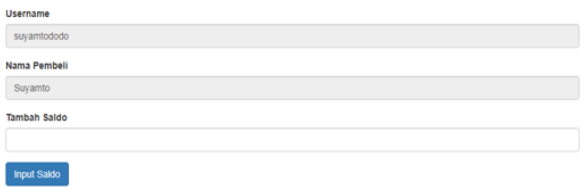

A ERD 9 |W Pाल

Gambar 19. Halaman Tambah Saldo

\section{IV.KESIMPULAN}

Berdasarkan hasil analisis dan perancangan sistem Aplikasi E-money pada pasar mahasiswa Sekolah tinggi teknologi Tanjungpinang dapat disimpulkan sebagai berikut::

1. Sistem yang diraincang ini bertujuan mempermudah tugas pencatatan transaksi antara pengunjung dan penjual..

2. Aplikasi E-money pada pasar mahasiswa STT indonesia ini dibuat menggunakan bahasa pemrograman php.

3. Aplikasi E-money pada pasar mahasiswa STT indonesia digunakan saat berlangsungnya pasar mahasiswa

\section{UCAPAN TERIMA KASIH}

Dalam kesempatan ini penulis ingin mengucapkan terimakasih kepada semua pihak yang telah membantu dalam penyelesaian penelitian ini khususnya kepada dosen pembimbing dan seluruh civitas akademika kampus STTI

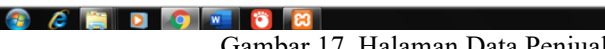

13. Halaman Data Pembeli

[1] Winarno, Edy, Pembangunan aplikasi child tracker berbasis assisted global positioning system (a-gps) dengan platform android hal 2.2013 
Bangkit Indonesia, Vol. VIII, No. 02, Bulan Oktober 2019

[2] Internet, TMN Redaksi, Malahng: PT. Tokoteknologi Mikroelektronik Nusantara, Ed. I, 2015.

[3] Lisdianto, Sarana Informasi Kepegawaian pada Badan Kepegawaian Daerah Kota Tanjungpinang Berbasis WEB, 2015 [Kuliah], STT Indonesia Tanjungpinang, Oktober 2015.

[4] Implementasi Model View Controller Dengan Framework Codeigniter Pada E- Com-merce Penjualan Kerajinan Bali. Jurnal Sistem Dan Informatika, Vol. 11 No. 1.

[5] Arief, M. Rudyanto. 2011. Pemrograman Web Dinamis Menggunakan PHP \& MySQL. Yogyakarta

[6] AnsariSaleh Ahmar, Modifikasi CMS Template Lokomedia [Garudhawaca, yogayakarta,2013], hal.11.

[7] Adi Nugroho, Analisa dan Perancangan Sistem Informasi dengan Metodologi Berorientasi Objek, [Andi, 2005, Yogyakarta], hal.125

[8] Al Fatta Hanif, Analisis \& Perancangan Sistem Informasi, Andi, 2007, Yogyakarta.

[9] Yakub, Pengantar Sistem Informasi, Graha Ilmu, 2014, Yograkarta.

[10] Hartono Mustakini, Analisis dan Design, Andi, 2009, Yogyakarta. 